Mr. Wilkinson also points out in his paper the necessity for the basilar membrane being continuous. If the fibres had gaps between them, no regular loading of the vibrating elements would be possible. W. M. BAyliss.

University of London, University College, Gower Street, W.C.I.

The description of Dr. Wilkinson's model of the cochlea in NATURE (October 2I, p. 559) recalls Dr. Yoshii's experiments on guinea-pigs. Yoshii operated with long-sustained notes from whistles of different pitches, and concluded from the resulting lesions in the organ of Corti that the pitch of the note determines the region of maximal displacement of the basilar membrane. But as he used the same pressure to blow the different whistles (Zeitschr. f. Ohrenheilkunde, 58, I909, p. 205), the product $a^{2} n^{2}$ had a constant value, i.e. the greater the frequency of the note employed, the less the amplitude of its vibrations, which shows at once that Yoshii's results do not support his conclusions. If Dr. Wilkinson's model of the cochlea is a good one, it will show that the locus of maximal vibration in the basilar membrane for a given note shifts toward the distal end when the intensity of that note is increased, and toward the fenestral end when its intensity is diminished; and will thus demonstrate once again that the principle of resonance can find no application in the internal ear.

University of London, University College, Gower Street, W.C.I, October 26.

\section{An Empire Patent.}

IN the article appearing in NATURE for September 30 , p. 437 , with the above heading, there is the underlying assumption that the status of the inventor should be assimilated to that of the author, namely, that both should be secured a world-wide monopoly at a minimum expenditure. Will you allow me to present in your columns a more philosophical view of the history and function of patent law in relation to the growth and decay of civilisation, from which it will be seen that the favourable treatment of the inventor cannot be based upon international principles. It is part and parcel of a purely national and competitive policy.

The processes by which the characteristics of a higher civilisation are transmitted to races of lower culture appear to be based ultimately upon biological laws. Pressure generated within the walls of the higher civilisation drives out its more enterprising citizens to seek their fortunes elsewhere, and the new colonists, by interbreeding with the native stock, impart to it their own superior characteristics. The outward forces tending to the disruption of the older organisation may be economic, religious, or political, or some combination of these. The process may occupy centuries or be accomplished within as many decades. Thus the industrialisation of the English occupied many centuries-the periods of advance in the reigns of Edward III., Elizabeth, and Charles II. being associated with large influxes of the industrial population of the Continent. On the other hand, the rapid rise of the United States to the rank of a first-class power has been the work of the past fifty years. In both these instances national development was preceded by conditions which favoured the introduction and assimilation of a higher strain from abroad. Maintaining a civilisation at a high level in turn rests upon its compliance with the same biological law.

Talent and enterprise are the natural monopoly of a relatively small fraction of the human race. These characteristics are transmitted by direct descent, reproducing themselves in successive generations. How closely the fortunes of an industry may be associated with particular family names-notwithstanding the dilution which each family undergoes by marriage-is not sufficiently recognised. It has, for example, been shown recently that iron founding was introduced into this country by a body of French workers in the reign of Henry VII. A leading family which came in at this period were the Leonards, members of which migrated to the United States in the seventeenth century; whence the saying arose, that "where you find ironworks there you find a Leonard." But there is some reason to suppose that the French iron-founders originally came from Italy. Hence the Leonardos, Lennards, or Leonards may trace their connexion with this industry perhaps for 500 years. This reappearance of the same characteristics in successive generations of a family, and the predominance of the imported families in the higher ranks of culture - other than that of administration-can be verified by reference to the National Directories. A Stirling is generally an engineer, a Hochstetter a mineralogist, a Matthiessen a physicist. These families form a cosmopolitan body whose services can be enlisted by any country which possesses the power and foresight to attract them. Thus the maintenance of a civilisation depends upon its power to retain the services of its best native stock, while constantly reinforcing it from outside sources.

At an early period in the history of this country, bringing in companies of skilled artisans from abroad became an accepted feature in the exercise of the Royal prerogative. In the reign of Elizabeth a new feature was introduced, whereby, in addition to the Royal protection and favour, an exclusive right of manufacture was granted to any institutor of a manufacture not in use within the realm at the date of the Letters Patent. This system, though opposed to the tenets of the Common Law, received a grudging recognition in the Statute of Monopolies in 1624. Under this Statute the rights of the native inventor rested on the fact of his profession that he was willing and able to institute a new industry. The efficacy of the law rested upon two principles: that it attracted foreign strains of inventive ability, while stimulating that of the native inventor. Anthropologists are agreed that there is a fairly equal distribution of ability in different races. The English Crown recognised the deficiency in native stock and made good its defects by selective racial interbreeding.

The first blow to the efficiency of the English patent system was struck in the last quarter of the eighteenth century by a judge of the King's Bench. It is well known that there is a remarkable hiatus in the continuity of patent law decisions for the century and a half subsequent to the Statute of Monopolies. The reason for this is now clear. The Crown, notwithstanding the provisions of the above Statute, successfully maintained the right of disposing of its own grants by constituting the Privy Council the Court before which alone the validity of patent rights could be adjudicated. In spite of the more than doubtful character of its jurisdiction, the Council proved a most competent and business-like tribunal. It never lost sight of the real object of the law. Hence proposals for instituting new industries were not allowed to drop if a suitable applicant for the NO. 2767 , VOL. I IO] 